\title{
Effects of colored contrast of mobile websites on behavioral intentions
}

\author{
Pelet, Jean-Eric ${ }^{a}$ and Taieb, Basma ${ }^{b}$ \\ ${ }^{a}$ Department of Marketing, KMCMS.net, ISC Business School, University of Nantes, \\ France, ${ }^{b}$ Department of Marketing, University of Cergy Pontoise, France
}

\begin{abstract}
This study examines the effects of the mobile-phone website colored contrasts and the affective states of the consumer (emotions and moods) and trust respectively on intention to revisit, buy on and recommend the mobile website. For this purpose, a factorial plan $2 \times 2$ was developed and a mobile website, with two different alternatives, was designed especially for the experiment: positive contrast (yellow text on green background) and negative contrast (green text on yellow background). The research was conducted on French consumers. 312 valid responses were collected through online and personal survey questionnaires. Data was analysed using the method of structural equations. The results show the significant effects of mobile website's color contrast on behavioral intentions. Perceived dominance and trust towards the website have positive effects on behavioral intentions, whereas mood has non-significant effects on behavioral intentions.
\end{abstract} Managerial implications are discussed.

Keywords: m-commerce, color, contrast ratio, dominance, trust, behavioral intention. 


\section{Introduction}

Reading through the screen of a smartphone in the street can sometimes prove to be a nightmare, especially when the sun shines, and when legibility conditions are not very good. Brands that don't pay attention to the ease of reading the content of their mcommerce (mobile commerce) website may lose consumers' intentions to buy and revisit as well as their intentions to recommend the website. To that extent, the contrast ratio created by the foreground (text) and background colors of the website need to be carefully designed. As already mentioned by Pelet (2014) regarding e-commerce, color contrast of the website enhances the memorization of information and the intention to purchase (Pelet \& Papadopoulou, 2010, 2012). Especially in the context of the Web design, color serves as a support to the layout of the information. Hence, it works as a contrasting base. Reading time is shorter when there is good contrast. Also, reading is more enjoyable due to the correlation with improved legibility. Some studies show that a positive contrast obtained with a light text over a dark background provokes online visitors to abandon a website and puts users in a negative mood (Pelet, 2010). A positive contrast inflicts a visual strain accompanied by eye fatigue, contrary to a negative contrast (a dark text over a light background). This is why we choose to distinguish the background and foreground colors in the experiment we will present hereafter, by using both negative and positive contrasts to conduct our measurements. The positive contrast being yellow on green, and the negative one being green on yellow, following Hill \& Scharff's (1997) findings.

This paper presents a literature review on the importance of the colored contrast of mobile website interfaces, placing importance on emotions and dominance in particular, the mood and trust of users regarding the website. The methodology section then presents the website built for the experiment, followed by results aiming at highlighting the behavioral intentions derived from positive and negative colored contrasts exhibitions. We conclude the paper with a discussion, some limits and future research pathways, affording some managerial implications.

\section{Literature review}

\subsection{Controlling the Contrast Ratio of Mobile Website's Interfaces}

Initial feelings of the users are so crucial because during the first 50 milliseconds they decide whether to continue browsing the website or not (Lindgaard et al., 2006). The aim of designers is therefore to provide interactive systems that are not only useful and usable, but are also capable of transmitting positive emotions through their aesthetic characteristics.

Practitioners are advised to emphasize strong contrast between the foreground and background, especially for text messages. An important factor is appearance, especially proper choice of font and color contrast, which creates reliability and enhances e-service 
quality or perception if the website is user friendly (Lowry et al., 2014). Thus, we can hypothesize:

H1. The color contrast of the mobile website positively influences behavioral intentions

\subsection{Emotions and Mood's Effects on Behavioral Intentions}

When consumers buy on the Web, they fulfill certain tasks that can elicit responses in both cognition and affect. These responses can determine the intention of the consumer to return to the site (Koufaris, 2002). In the context of electronic commerce, more specifically, the perceived control or the feeling of dominance, has been studied as an experiential factor that can influence the attitudes and behavioral intentions of users (Mazaheri et al., 2011). Hence, we assume the following hypothesis:

H2. The perceived dominance when visiting the mobile website positively influences behavioral intentions

Previous research has indicated that people in different mood states tends to process information differently (e.g. Kim et al., 2015). Indeed, people in a positive mood avoid spending cognitive effort whereas people in a negative mood process information more centrally. A good mood may contribute to consumers' intention to return to a website at which they have made previous purchases (Wu et al., 2008). Therefore, we can hypothesize:

H3. The mood of the consumer when visiting the mobile website has an influence on behavioral intentions

\subsection{Online Trust Induces Better Behavioral Intentions}

The lack of trust is one of the reasons most frequently cited by consumers who do not buy on the Internet (Mukherjee \& Nath, 2007). Previous research has shown that trust towards the website can have a significant and positive influence on behavioral intentions of consumers in terms of repeat visits, purchase intention, and positive word-of-mouth (Mukherjee \& Nath, 2007). We assume the following hypothesis:

H4. Trust towards mobile website positively influences behavioral intentions

Coming from these hypotheses, we propose the following conceptual model:

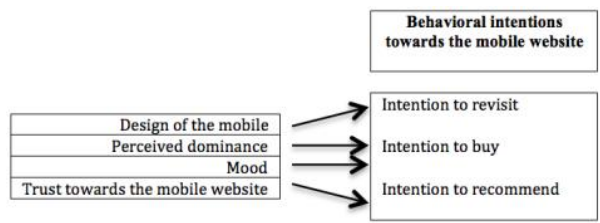

Figure 1. Conceptual model 


\section{Methodology}

\subsection{Conditions of the Survey, Stimuli and Data Collection}

Respondents answered the questionnaire in the real-life, outdoor conditions of using a smartphone. For this reason, respondents were tested for color blindness using the Ishihara test $^{1}$ (Pelet, 2010). This guaranteed the validity of our sample's responses, by keeping people with perfect color vision. In order to control environmental variables - ambient lighting $^{2}$, humidity ${ }^{3}$ and temperature ${ }^{4}$ were also measured during each respondent's visit. These measurements enabled us to neutralize variables and were reported on each questionnaire of each respondent.

Two versions of a mobile website specializing in the sale of music CDs, have been specially designed for this experimental study: a site with a positive contrast (yellow text on a green background) and another with a negative contrast (green text on a yellow background). The experimental site contains $30 \mathrm{CDs}$ available in 10 categories (3 CDs / category). For each $\mathrm{CD}$, participants could see the $\mathrm{CD}$ cover, the album title, the artist name and other details (music category, status (new or used), price, time delivery...).

312 participants visited the site's two versions: 160 participants for the site with positive contrast and 152 participants for the site with negative contrast. Each participant had to view the details of at least two CDs of their choice and add them to their cart without making real purchases. After viewing at least two CDs, a link appeared asking them to respond to a questionnaire.

The questionnaire includes measures related to site design (5 items borrowed from Bressolles, 2006), perceived dominance (5 items of Mazaheri et al., 2011), mood (5 items borrowed from Mayer \& Gaschke, 1988) trust towards the website (7 items of Chung \& Shin, 2009), intention to revisit (3 items of Mukherjee \& Nath, 2007), purchase intent (4 items of Limayem \& Rowe, 2006) and intention to recommend (3 items of Goyetteet al., 2010).

\subsection{Validation of Measurement Scales}

The measurement scales have a good internal consistency (Cronbach $\alpha$ and $\rho$ of Jöreskog are above 0.7 ). The variance extracted (AVE) by items is greater than 0.5 . The variance

\footnotetext{
1 The Ishihara test is the most common color-blindness test used today (Deeb \& Motulsky, 2011). It consists of a number of plates, 24 or 38, the Ishihara plates, each containing a circle of dots which appear in random colors and sizes. Within the circle there are dots forming a number which should be clearly visible to viewers with normal color vision and hard to see or invisible to viewers with defective color vision. To pass the test participants should recognize the number in every plate.

2 an interval between 300 lux and 500 lux was fixed

3 a maximum of $65 \%$ humidity was retained

4 data was collected when the temperature ranged from 19 to $29^{\circ} \mathrm{C}$
} 
extracted by each construct is greater than the squared correlations among constructs (Fornell \& Larker, 1981), thus discriminant validity was supported. The indices for the measurement model also indicate a good fit $\left(\mathrm{RMSEA}=.08, \mathrm{RMR}=.03, \chi^{2} / \mathrm{df}=3.27, \mathrm{p}<\right.$ $.01)$.

\subsection{Hypothesis Testing}

The hypotheses were tested using the method of structural equations (AMOS). Their validity has been verified for mobile websites with positive and negative contrast. The results are presented in Table 1 below.

\section{Table 1. Test of the hypotheses}

\begin{tabular}{|c|c|c|c|c|c|c|c|c|}
\hline & \multicolumn{3}{|c|}{$\begin{array}{c}\text { Site with negative contrast } \\
\text { (Green text on a yellow } \\
\text { background) }\end{array}$} & & \multicolumn{3}{|c|}{$\begin{array}{c}\text { Site with positive contrast } \\
\text { (Yellow text on a green } \\
\text { background) }\end{array}$} & \\
\hline & Estim & S.E. & C.R. & & Estim & S.E. & C.R. & \\
\hline $\begin{array}{l}\text { Revis<--- } \\
\text { Desig }\end{array}$ & .10 & .04 & $2.73 * *$ & \multirow[t]{3}{*}{$\begin{array}{l}\text { H1 partially } \\
\text { supported }\end{array}$} & .23 & .03 & $7.00 * *$ & \multirow[t]{3}{*}{ H1 supported } \\
\hline $\begin{array}{l}\text { Buy<--- } \\
\text { Desig }\end{array}$ & .02 & .04 & 0.36 & & .20 & .04 & $5.30 * *$ & \\
\hline $\begin{array}{l}\text { Recom<--- } \\
\text { Desig }\end{array}$ & .16 & .04 & $4.40 * *$ & & .17 & .03 & $5.21 * *$ & \\
\hline $\begin{array}{l}\text { Revis<--- } \\
\text { Dom }\end{array}$ & .33 & .05 & $6.35 * *$ & \multirow[t]{3}{*}{ H2 supported } & .17 & .05 & $3.79 * *$ & \multirow[t]{3}{*}{$\begin{array}{l}\text { H2 partially } \\
\text { supported }\end{array}$} \\
\hline $\begin{array}{l}\text { Buy<--- } \\
\text { Dom }\end{array}$ & .22 & .05 & $4.12 * *$ & & .24 & .05 & $4.57 * *$ & \\
\hline $\begin{array}{l}\text { Recom<--- } \\
\text { Dom }\end{array}$ & .11 & .05 & $2.49 *$ & & -.03 & .04 & -.71 & \\
\hline $\begin{array}{l}\text { Revis<--- } \\
\text { Mood }\end{array}$ & -.19 & .11 & -1.79 & \multirow[t]{3}{*}{$\begin{array}{c}\text { H3 non } \\
\text { validated }\end{array}$} & .05 & .08 & .64 & \multirow[t]{3}{*}{$\begin{array}{c}\text { H3 non } \\
\text { validated }\end{array}$} \\
\hline $\begin{array}{l}\text { Buy<--- } \\
\text { Mood }\end{array}$ & -.19 & .12 & -1.58 & & .10 & .09 & 1.04 & \\
\hline $\begin{array}{l}\text { Recom<--- } \\
\text { Mood }\end{array}$ & -.06 & .10 & -0.57 & & .09 & .09 & 1.06 & \\
\hline $\begin{array}{l}\text { Revis<--- } \\
\text { Trust }\end{array}$ & 1.07 & .08 & $12.86 * *$ & \multirow[t]{3}{*}{ H4 supported } & 1.19 & .09 & $12.95 * *$ & \multirow[t]{3}{*}{ H4 supported } \\
\hline $\begin{array}{l}\text { Buy<--- } \\
\text { Trust }\end{array}$ & 1.15 & .09 & $12.19 * *$ & & .98 & .09 & $10.44 * *$ & \\
\hline $\begin{array}{l}\text { Recom<--- } \\
\text { Trust }\end{array}$ & 1.03 & .08 & $13.32 * *$ & & 1.2 & .09 & $13.76^{* *}$ & \\
\hline
\end{tabular}

Note: $* * \mathrm{p}<.01 ; * \mathrm{p}<.05$

Results show that the website's positive contrast has a significant impact on purchase, revisit and recommendation intentions. Trust towards the website has very significant effects on behavioral intentions regardless of the positive or negative contrast. The perceived dominance has an impact only on purchase and revisit intentions when the 
contrast is positive. No significant effect was found for the mood regardless of contrast. Unlike the site with positive contrast, the website's negative contrast does not influence purchase intent. Finally, the dominance has an impact on the intention to recommend when the contrast is negative.

\section{Discussion, Limits and Future ways of Research}

Our results show that the color contrast of the m-commerce website, in particular a positive contrast, strongly influences the consumer's behavioral intentions. It should also be noted that the consumer would be more inclined to buy from the mobile website with a positive contrast (in our case, a yellow text on a green background). On a mobile website, in the outdoor conditions of the experimentation, respondents have better behavioral intentions when the contrast ratio is a bright text over a dark background, which is the opposite of most actual mainstream websites, which use dark texts (such as a black ones) over bright backgrounds (such as white ones).

In conditions where the sun shines and where it is often quite difficult to read on the smartphone screen, users seem to prefer positive contrasts. Interestingly, this contrast is exists in any smartphone as an "accessibility" option, in the "View" folder of the "Settings" section when pressing the "Negative Colors" button. However, it is not very easy to set up, especially when the lighting conditions are difficult, such as when the sun shines. An initial managerial implication of this research could therefore be to make this service available when the image sensor of the smartphone detects the sunshine and switches it on when it reaches a certain level. This would enhance the legibility of the screen and preserve users' eyes at the same time. A second managerial implication that comes from this finding is that it could save the smartphone battery somewhat. It uses more energy to show a bright screen than a dark one. This is why our smartphone turns off relatively quickly when we don't touch its screen: in order to preserve the battery life, the more it shows a black screen, the less energy it uses. A website that is predominantly dark colors rather than bright colors may help to save the battery life and therefore preserve the environment: it becomes an "eco-friendly" strategy for the brands which will work in this way and make users "Socially Conscious Consumers" as depicted by Brooker (1976). The second result is in line with the preliminary one, showing that the perceived dominance when visiting the $\mathrm{m}$-commerce website positively influences behavioral intentions: a user who can easily read the screen may feel more confortable and by extension have a greater feeling of dominance with the m-commerce website's interface. The user knows exactly what he can do with the website he is viewing, because everything seems clear to him. Such a feeling reinforces the importance of ergonomics where the content must be easy-to-use and agreable to read and understand. We finally found that trust in the mobile website positively influences behavioral intentions. These results support previous work in e-commerce (e.g. Pelet \& Papadopoulou, 2012). 
Our study contributes to a better understanding of consumer behavior using mobile websites, nevertheless, some limitations may be noted. Consideration of other variables such as feelings of privacy and perceptions of waiting time could provide more details on the purchasing behavior of people with sight problems. While maintaining constant levels of brightness and saturation, which are two components of color (along with hue) to study the overall effect of color on behavioral intentions without distinguishing the effect of text color from background color is one limitation of this research. Future studies are advised to consider others colors and to examine separately the effect of background color, and text color, as well as the interaction between the two. Moreover, there's still no agreement on whether human reactions to color are innate or are learned and can be conditioned by each individual's social experience (Crozier, 1999). Cultural aspects must also be taken into consideration in as far as we perceive color differently according to our origins.

Whereas smartphones continue to offer more and more graphic possibilities thanks to their ever growing power, enabling them to show more than 16 billion colors, our eyes enable us to disinguish only 8 billion (Chrisment et al., 1994). Among the latter, it is easy to create contrast ratios enabling users suffering from color-blindness, as well as other sight problems, using free and easy-to-use tools (for a list of them, please visit http://www.scoop.it/t/color). As already described by Pelet \& Papadopoulou (2012), by taking into account the W3C and Web Accessibility Initiative (WAI) guidelines ${ }^{5}$, the use of color becomes more professional and the choices web designers make are more informed in terms of usability, as well as in terms of human-computer interaction in general.

\section{References}

Bressolles, G. (2006). La qualité de service électronique: NetQu@1Proposition d'une échelle de mesureappliquéeauxsitesmarchandseteffetsmodérateurs. Recherche et Applications en Marketing, 21(3), 19-45.

Brooker, G. (1976).The self-actualizing socially conscious consumer. Journal of Consumer Research, 3(2), 107-112.

Chrisment, A., Durchon, P., Lanthony, P., \& Tavernier, I. (1994). Communiquer par la couleur - Mesurer, Reproduire, Observer, Vivre la couleur. Paris, 3C Conseil.

Crozier, W.R. (1999). The meanings of colour: preferences among hues. Pigment and Resin Technology, 28(1), 6-14.

Deeb, S.S. \& Motulsky, A.G. (2015). Red-Green Color Vision Defects. retrieved from the Internet at http://www.ncbi.nlm.nih.gov/books/NBK1301/October 12, 2015.

\footnotetext{
5 The Web Access Initiative (WAI) works with the W3C (World Wide Web Consortium) working groups to address and improve accessibility within specifications and $\mathrm{W} 3 \mathrm{C}$ technologies.
} 
Fornell, C., \& Larcker, D.F. (1981). Evaluatingstructuralequationmodels with unobservablevariables and measurementerror. Journal of Marketing Research, 18(1), 39-50.

Goyette, I., Ricard, L., Bergeron, J., \& Marticotte, F. (2010). e-WOM Scale: word of mouth measurement scale for e-services context. Canadian Journal of Administrative Sciences/Revue Canadienne des Sciences de l'Administration, 27(1), 5-23.

Hill, A., \& Scharff, L.V. (1997). Readability of websites with various foreground/background color combinations, font types and word styles.In Proceedings of 11th National Conference in Undergraduate Research, 2, 742-746.

Kim, H., Choi, Y., \& Lee, Y. (2015). Web atmospheric qualities in luxury fashion brand websites. Journal of Fashion Marketing and Management, 19(4), 384-401.

Koufaris, M. (2002). Applying the technology acceptance model and flow theory to online consumer behavior. Infomation System Research, 13(2), 205-224.

Limayem, M., \& Rowe, F. (2006). Comparaison des facteursinfluençant les intentions d'achat à partir du Web à Hong Kong et en France: influence sociale, risques et aversion pour la perte de contact, Revue Française du Marketing, 209(4/5), 25-48.

Lindgaard, G., Fernandes, G., Dudek, C., \& Brown, J. (2006). Attention Web designers: You have 50 milliseconds to make a good first impression. Behavioral Information Technology 25(2), 115-126.

Lowry, P.J., Wilson, D.W., \& Haig, W.L. (2014). A picture is worth a thousand words: Source Credibility Theory applied to logo and website design for heightened credibility and consumer trust. International Journal of Human-Computer Interaction,30(1),63-93.

Mayer, J.D., \& Gaschke, N.Y. (1988). The experience and meta-experience of mood, Journal of personality and social psychology, 55(1), 102-111.

Mazaheri, E., Richard, M.O., \& Laroche, M. (2011). Online consumer behavior: Comparing Canadian and Chinese website visitors. Journal of Business Research, 64(9), 958-965.

Mukherjee, A., \& Nath P. (2007). Role of electronic trust in online retailing: A reexamination of the commitment-trust theory. European Journal of Marketing, 41(9/10), 1173-1202.

Pelet, J.-É., (2014). Investigating the Importance of Website Color Contrast in ECommerce: Website Color Contrast in E-Commerce. In Khosrow-Pour, M. (2015). Encyclopedia of Information Science and Technology, Third Edition (10 Volumes). Hershey, PA: IGI Global.

Pelet, J.-É., \& Papadopoulou, P. (2012). The effect of colors of e-commerce websites on consumer mood, memorization and buying intention. European Journal in Information Systems, 21(4), 438-467.

Pelet, J.-É. (2010). Effets de la couleur des sites web marchands sur la mémorisation et sur l'intention d'achat. Systèmes d'Information et Management, 15(1), 97-131.

Wu, C.S., Cheng, F.F., \& Yen, D.C. (2008). The atmospheric factors of online storefront environment design: an empirical experiment in Taiwan. Information \& Management, 45(7), 493-498. 